\title{
Substance $P$ stimulates human airway submucosal gland secretion mainly via a CFTR-dependent process
}

\author{
Jae Young Choi,,1,2 Monal Khansaheb,,1,3 Nam Soo Joo, ${ }^{1}$ Mauri E. Krouse, ${ }^{1}$ Robert C. Robbins, ${ }^{4}$ \\ David Weill, ${ }^{5}$ and Jeffrey J. Wine ${ }^{1}$

\begin{abstract}
${ }^{1}$ Cystic Fibrosis Research Laboratory, Stanford University, Stanford, California, USA. 2Department of Otorhinolaryngology, Yonsei University, Seoul, Republic of Korea. ${ }^{3}$ Department of Pediatrics, UCSF, San Francisco, California, USA. ${ }^{4}$ Department of Cardiothoracic Surgery and
\end{abstract} \\ ${ }^{5}$ Department of Pulmonary and Critical Care Medicine, Stanford University School of Medicine, Stanford, California, USA.
}

\begin{abstract}
Chronic bacterial airway infections are the major cause of mortality in cystic fibrosis (CF). Normal airway defenses include reflex stimulation of submucosal gland mucus secretion by sensory neurons that release substance $P$ (SubP). CFTR is an anion channel involved in fluid secretion and mutated in CF; the role of CFTR in secretions stimulated by SubP is unknown. We used optical methods to measure SubP-mediated secretion from human submucosal glands in lung transplant tissue. Glands from control but not CF subjects responded to mucosal chili oil. Similarly, serosal SubP stimulated secretion in more than $60 \%$ of control glands but only $4 \%$ of CF glands. Secretion triggered by SubP was synergistic with vasoactive intestinal peptide and/or forskolin but not with carbachol; synergy was absent in CF glands. Pig glands demonstrated a nearly 10-fold greater response to SubP. In 10 of 11 control glands isolated by fine dissection, SubP caused cell volume loss, lumen expansion, and mucus flow, but in 3 of 4 CF glands, it induced lumen narrowing. Thus, in CF, the reduced ability of mucosal irritants to stimulate airway gland secretion via SubP may be another factor that predisposes the airways to infections.
\end{abstract}

\section{Introduction}

Cystic fibrosis (CF) is caused by mutations that disrupt CFTR, an anion channel that mediates fluid secretion in many epithelia. The most serious consequence of $\mathrm{CF}$ is respiratory failure caused by chronic bacterial airway infections, which motivates research to understand the link between loss of CFTR function and airway infections. In the airways, CFTR is found in both the surface ciliated epithelial cells and in serous cells of submucosal glands (1-3). At both sites, it helps mediate fluid secretion that hydrates mucins and other innate defense molecules elaborated primarily by the glands $(4,5)$. The resulting bacteriostatic mucus is efficiently transported out of the airways, keeping normal airways sterile. In CF, CFTR-dependent anion and fluid secretion by both surface epithelia and glands is lost $(6,7)$, but absorption is increased (reviewed in ref. 8), and it has been hypothesized that hyposecretion/hyperabsorption leads to defective mucus clearance (9) that compromises innate mucosal defenses and predisposes CF airways to chronic infections $(5,7,10-24)$. Fortunately, CFTR-independent mechanisms exist for fluid secretion in both surface epithelia and glands so that some innate defense persists. Current treatments for CF airways disease often engage these CFTR-independent secretion pathways (8), and such strategies might be improved if we had a better understanding of CFTR's role in airway innate defense.

Submucosal glands produce most upper airway mucus $(25,26)$, and in experiments using tracheal xenografts, with and without

Conflict of interest: The authors have declared that no conflict of interest exists. Nonstandard abbreviations used: $\mathrm{ACh}$, acetylcholine; $\left[\mathrm{Ca}^{2+}\right]_{i}$, intercellular $\mathrm{Ca}^{2+}$ concentration; $[\mathrm{cAMP}]_{\mathrm{i}}$, intercellular cAMP concentration; $\mathrm{CF}$, cystic fibrosis; COPD, chronic obstructive pulmonary disease; DC, disease control; DIC, differential interference contrast; $\mathrm{HN}$, human normal; SubP, substance P; VIP, vasoactive intestinal peptide.

Citation for this article: J. Clin. Invest. 119:1189-1200 (2009). doi:10.1172/JCI37284. glands, the gland-containing xenografts elaborated much more lysozyme and were much more effective in resisting infections (27). Airway glands are controlled by autonomic efferent innervation from airway intrinsic neurons that release multiple neurotransmitters, including acetylcholine (ACh), vasoactive intestinal peptide (VIP), substance $\mathrm{P}$ (SubP), and NO, as well as by mediators like histamine, bradykinin, and $\mathrm{PGE}_{2}$ (reviewed in ref. 17). Glands also receive SubP via axon reflexes from C fiber afferents. We are attempting to understand the roles these different agonists play in controlling the glands and the extent to which the secretion they stimulate is CFTR dependent; such information is essential if we are to understand the role of CFTR-mediated secretion in airway innate defenses.

In prior studies, we found that while ACh can still stimulate secretion from CF airway glands, fluid secretion stimulated by VIP is absent (7). The difference was attributed to the ability of ACh to elevate intercellular $\mathrm{Ca}^{2+}$ concentrations $\left(\left[\mathrm{Ca}^{2+}\right]_{\mathrm{i}}\right)$ and engage nonCFTR anion channels, and this has now been validated in studies of mouse submucosal glands $(28,29)$. SubP, like ACh, appears to elevate $\left[\mathrm{Ca}^{2+}\right]_{\mathrm{i}}$ in most systems, and in pig bronchi, SubP is more potent and has similar efficacy as ACh in stimulating gland mucus secretion $(26,30)$. This suggests that SubP, like ACh, may act in part via a $\mathrm{Ca}^{2+}$-dependent, CFTR-independent process in pigs. However, when testing mucus secretion from airway glands in mice, Ianowski et al. found that SubP stimulation was a much less effective agonist than cholinergic stimulation (31) and that unlike cholinergic stimulation, which produces equivalent secretion in WT and $\mathrm{Cftr}^{-1}$ mice (18), SubP was completely ineffective in producing mucus secretion in $\mathrm{Cftr}^{-/}$mice (31). Hyposecretion of mucus by CF airway glands may seem counterintuitive, given the copious sputum that is a hallmark of CF airways disease. However, there is a growing realization that excess sputum occurs in part as a consequence of overproduc- 

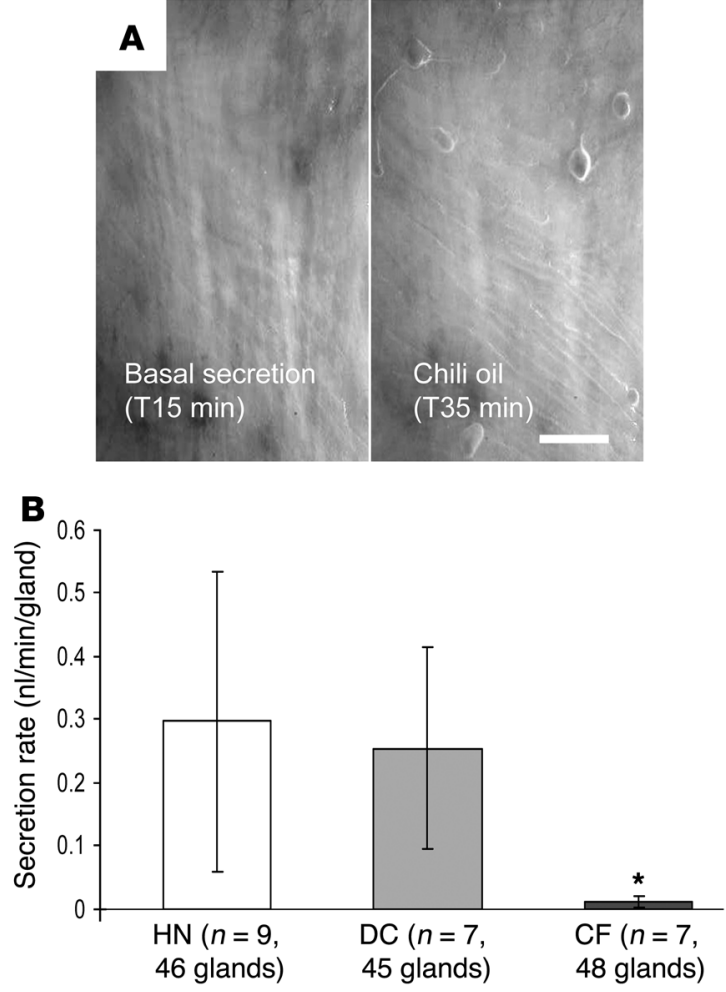

tion secondary to chronic airway infection and inflammation and in part due to increased difficulty of clearing the CF sputum unobtrusively via mucociliary clearance and swallowing (32).

Given these large species differences in airway gland responses of mice and pigs to SubP, it became essential to determine the responses of human airway glands to SubP. Surprisingly, in the present work, we show that humans resemble mice more than pigs, with regard to their airway gland responses to SubP. In humans as in mice, SubP is a much less effective agonist than ACh (carbachol), and overt fluid secretion stimulated by SubP is almost completely lacking in human CF glands, although morphological changes in the CF glands can still be observed using differential interference contrast (DIC) optics. Based on synergy between SubP and saturating concentrations of forskolin, we suggest a model in which CFTR-dependent secretion stimulated by SubP is produced by a mechanism other than merely elevating $[\mathrm{cAMP}]_{\mathrm{i}}$.

\section{Results}

Human control glands but not CF glands secrete in response to mucosal chili oil. When droplets of chili oil were added to the mineral oil layer covering the mucosal surface of isolated human airway segments, quiescent glands from human normal $(\mathrm{HN})$ or disease control (DC) tissues began to secrete, but glands from CF airways did not (Figure 1). This result in humans recapitulates previously reported results for control and $\mathrm{Cft}^{-1-}$ mice (18). In any preparation, only a portion of viable glands responded (viability was tested with carbachol applied to the serosal side), and the average secretion rates for responding glands were approximately $10 \%$ of rates of response to $10 \mu \mathrm{M}$ carbachol.

Human control glands responded to SubP. SubP is the most likely transmitter for mediating the secretory responses to mucosal chili oil. Therefore, we applied SubP directly to the serosal side of our

\section{Figure 1}

In human airways, mucosal chili oil stimulates submucosal gland mucus secretion from control (HN and DC) but not CF subjects. (A) Images of mucus bubbles formed under oil at the orifices of single submucosal glands in response to stimulation via mucosal chili oil. At 15 minutes, $2 \mu \mathrm{l}$ of chili oil was added to the approximately 20-30 $\mu \mathrm{l}$ oil layer. No mucus secretion was seen during the 15-minute control period (left panel); the right panel shows the results 20 minutes later. Scale bar: $0.5 \mathrm{~mm}$. (B) Summary data showing average secretion rates $( \pm S D)$ for 20 -minute periods, following application of chili oil. If basal secretion was present in the control period, it was subtracted from the rates shown. The secretion rate for $\mathrm{CF}$ glands was less than control glands $\left({ }^{*} P<0.05\right.$ versus $\left.\mathrm{HN}+\mathrm{DC}\right)$.

human airway preparations, where it was able to access the glands directly. The results of these experiments were consistent with the results using chili oil. When isolated segments of tracheal or bronchial airways were stimulated with $1-100 \mu \mathrm{M}$ of serosal SubP, single glands started to secrete within 1-2 minutes and some but not all glands continued to secrete as long as SubP was present (Figure $2 \mathrm{~A})$. Only a portion of viable glands responded (Figure 2C). For $24 \mathrm{HN}$ subjects, $100 \%$ of subjects and 295 of 379 of viable glands responded. The proportion of viable glands responding to SubP per HN subject varied between 33\%-100\% (mean, $78 \% \pm 16 \%$ ). For 20 DC subjects, $95 \%$ of subjects and 175 of 293 of viable glands responded (25\%-100\% per responding subject; mean, $60 \% \pm 18 \%$ ).

A concentration-response relationship was established by measuring the amount of secretion during the first 15 minutes of stimulation with SubP in the constant presence of $1 \mu \mathrm{M}$ of phosphoramidon (Figure 3A). For this method, $V_{\max }=0.33 \pm 0.02 \mathrm{nl} /$ $\mathrm{min} /$ gland and $\mathrm{EC}_{50}=1.13 \pm 0.22 \mu \mathrm{M}$. Maximal secretion rates for responding glands in controls were approximately $10 \%$ of those seen with $10 \mu \mathrm{M}$ carbachol (Figure 3, B and C, and Figure 4A).

The time course of secretion stimulated by SubP characteristically had an early peak, followed by a more sustained response that was approximately one-third or less of the peak secretory rate (Figure 4A). This response profile essentially duplicated that seen for carbachol in sheep (33), pig (34) and human glands (see below), although the magnitude of the response was much smaller.

Human CF glands barely responded to serosal SubP. In contrast with controls, a significantly smaller proportion of viable glands in $\mathrm{CF}$ subjects responded to SubP (Figure 2, B and C, and Figure 3B). The mean percentage of responding CF glands was only $4 \% \pm 4 \%$, about $5 \%$ of the control percentages $(n=7$; only 5 of 112 viable glands responded; range, $0 \%-9 \%$ per subject with 4 subjects not responding). In the CF tissue with the highest proportion of responding glands (CF48, $\triangle$ F508 homozygous), 2 of 22 glands (9\%) secreted in response to SubP. For these 2 responding glands, the peak secretion rates observed were $3 \%$ and $6 \%$ of the subsequent responses to carbachol, both less than the $10 \%$ seen for control glands (Supplemental Figure 1; supplemental material available online with this article; doi:10.1172/JCI37284DS1). As will be shown below, a single gland acinus isolated from this same subject for DIC imaging showed clear (but transient) acinar secretion.

In the above analyses, we averaged secretion rates only for responding glands. The total volume of secretion for a unit area of membrane is equal to the number of responding glands multiplied by the gland secretion rate. The values in Figures 2 and 3 indicate that the total volume of secretion stimulated by SubP for CF tissues is approximately $0.4 \%$ of that control tissues. 
A
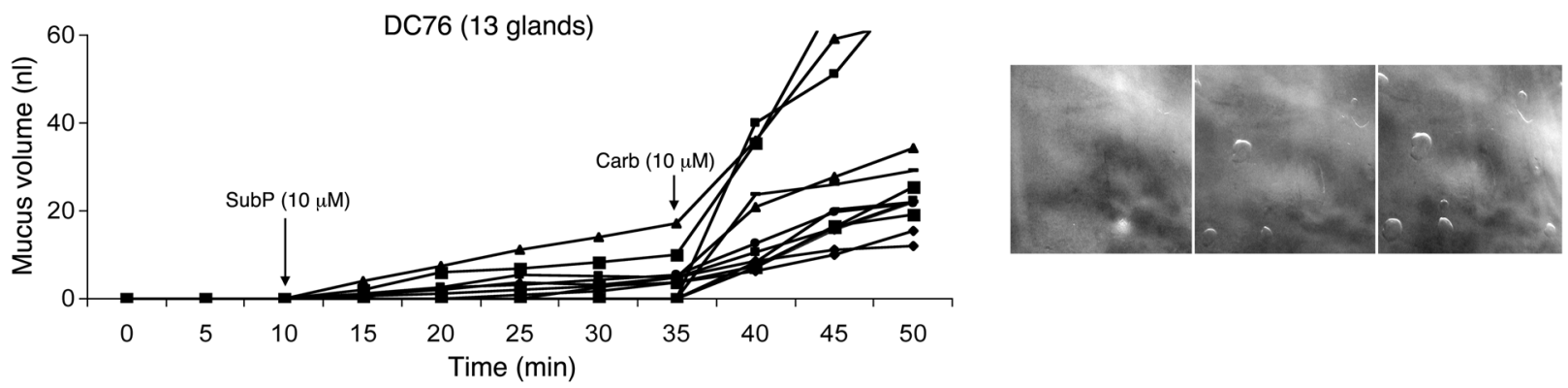

$\mathbf{B}$
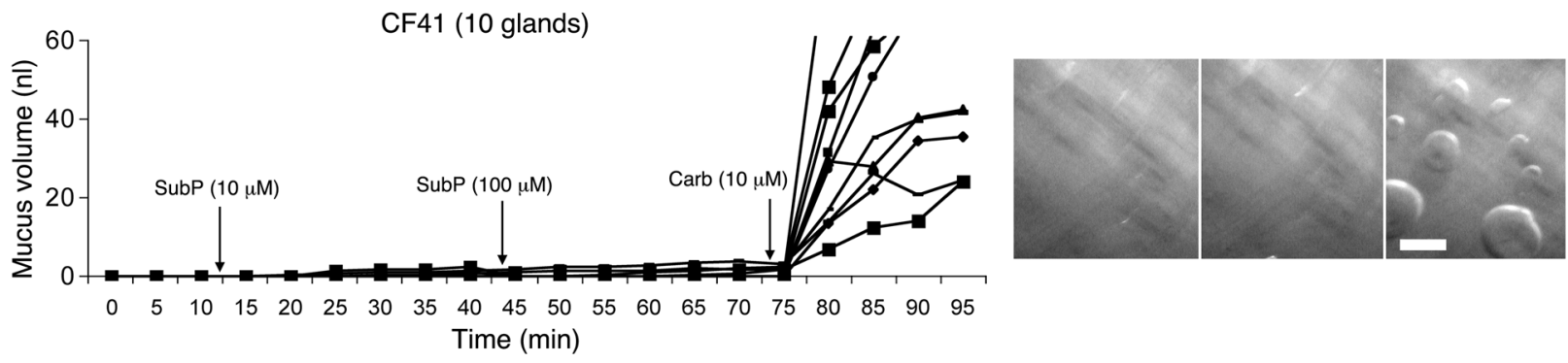

C

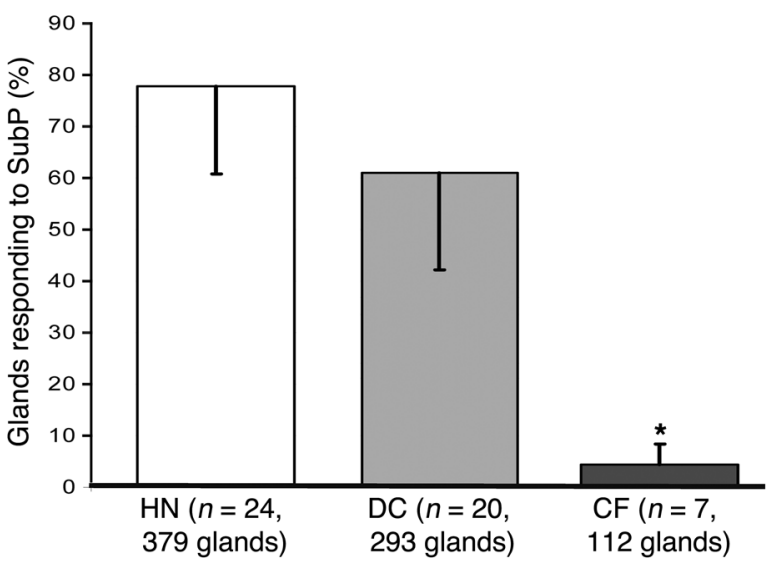

Figure 2

Serosal application of SubP-stimulated secretion from HN and DC but not CF airway glands. (A and B) Plots of secreted mucus volume over time for individual glands from $1 \mathrm{DC}$ and $1 \mathrm{CF}$ subject after stimulation are shown (each line represents a single gland). Right panels show part of the fields at end of 20 minutes of basal, SubP, and carbachol (carb) stimulation, respectively. Scale bar: $0.5 \mathrm{~mm}$. (C) SubP-stimulated secretion in a larger proportion of glands in $\mathrm{HN}$ or DC versus CF subjects. Each bar shows the mean percentage of viable glands that responded to SubP in HN, DC, and CF subjects. The total number of viable glands was defined as the number responding to 5 minutes of $10 \mu \mathrm{M}$ carbachol at the end of the experiment. Error bars show SEM. CF response to SubP was significantly less than that of either $\mathrm{HN}$ or $\mathrm{DC}$; ${ }^{*} P<0.05$.

Responses to SubP decreased with patient age in control subjects. Some evidence indicates possible age-related changes in airway innervation by peptide-containing nerves (35), so we plotted responsiveness as a function of patient age in HN, DC, and CF subjects. In controls, the proportion of responding glands decreased with age and with the presence of other diseases (Figure 4B). Because DC subjects were older on average than $\mathrm{HN}$ subjects, with little overlap (Figure 4B and Table 1), we are unable to determine conclusively whether age was the major variable accounting for the slight difference between the 2 groups. However, the youngest DC subject had a secretion rate equivalent to similarly aged $\mathrm{HN}$ subjects, and the oldest $\mathrm{HN}$ subject had a secretion rate equivalent to similarly aged DC subjects. By contrast, the CF subjects, who were on average the youngest, had by far the lowest proportion of responding airway glands (Figure 4B).

Rates of mucus secretion stimulated by SubP and carbachol were correlated. Because some control glands did not respond to SubP, we considered the possibility that a distinct set of SubP-responsive glands exists. To test this idea, we plotted peak secretion rates to SubP and carbachol on a gland-by-gland basis and obtained a positive correlation between the $2(r=0.76, P<0.0001$; Figure 5$)$. The different axes reflect the higher potency of carbachol, and the least squares line fit intercepted the $x$ axis for responses to SubP at a secretion rate of approximately $2 \mathrm{nl} / \mathrm{min} /$ gland for carbachol. (For 18 glands with a measured response of 0.0 to SubP, the mean secretion rate to carbachol was $1.3 \pm 0.2 \mathrm{nl} / \mathrm{min} /$ gland.) The relationship plotted in Figure 5 suggested that no special set of SubP responsive glands exists but rather that SubP is a weak agonist for all airway glands, so that glands with intrinsically lower secretion rates do not produce measurable mucus at the gland duct orifice. This result is consistent with prior results with carbachol and forskolin, in which we noted a large range of secretion rates among glands to both agonists $(7,33)$, with rates being positively correlated (34).

Gland secretion stimulated by SubP was synergistic with VIP and/or forskolin for control glands but not for CF glands. We observed synergistic increases in secretion rates when SubP was added to a saturating dose $(10 \mu \mathrm{M})$ of forskolin in HN or DC control glands (Figure 6, A and C). In contrast, CF glands showed almost no measurable secretion stimulated by these agents alone or in combination (Figure 6, $\mathrm{B}$ and $\mathrm{C}$ ). In Figure 6C, we normalized all secretion rates to peak secretion rates of carbachol; thus, the secretion rates are shown as fractions of the carbachol responses. Normalization decreases the variability inherent in the secretory responses of individual glands (see individual rates in Figure 6, A and B) and is appropriate because 

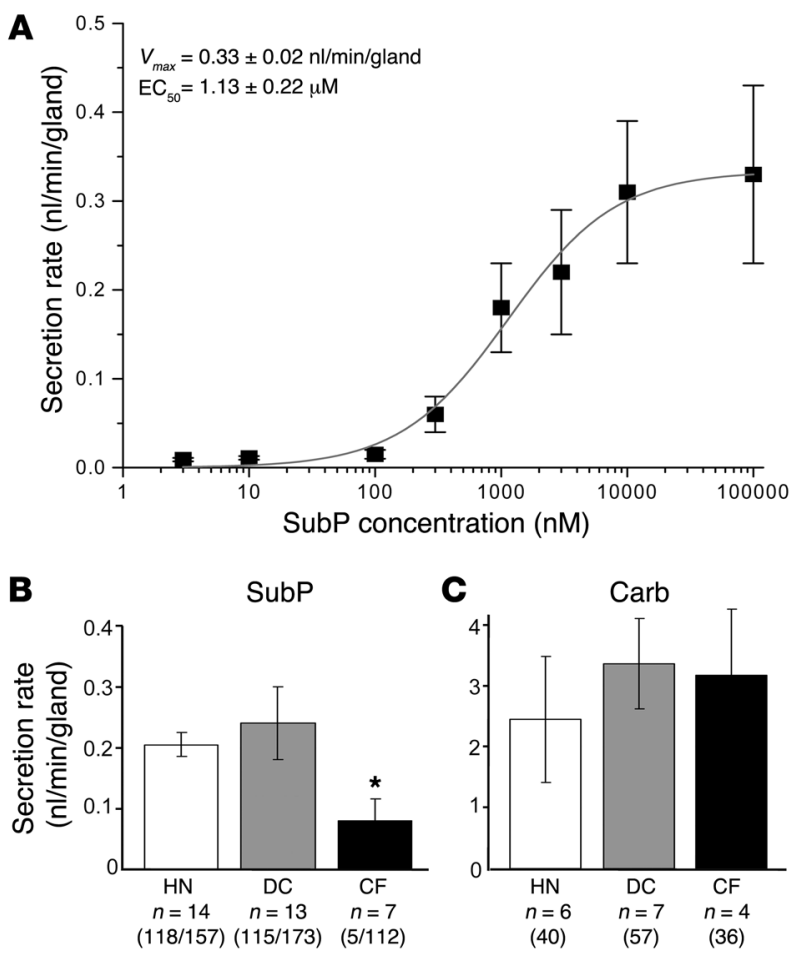

all groups have similar responses to carbachol (see Figure 3C). The addition of SubP to VIP and/or forskolin also increased the proportion of responding glands in 7 of 8 control subjects but not in any of $3 \mathrm{CF}$ subjects tested in this way (Supplemental Figure 2).

Evidence that SubP elevates $\left[\mathrm{Ca}^{2+}\right]_{i}$. In a previous study, we presented evidence that CFTR-dependent synergy between VIP or forskolin and low levels of carbachol resulted when activation of $\mathrm{Ca}^{2+}$-activated $\mathrm{K}^{+}$channels by carbachol increased the driving force for anions through CFTR (19). In this study, we used 3 methods to determine whether SubP might also elevate $\left[\mathrm{Ca}^{2+}\right]_{i}$ and activate $\mathrm{Ca}^{2+}$-activated $\mathrm{K}^{+}$channels: (a) We measured $\left[\mathrm{Ca}^{2+}\right]_{\mathrm{i}}$ with Fura-2; (b) we compared secretory responses to SubP in the presence and absence of the $\mathrm{Ca}^{2+}$ chelator BAPTA-AM; and (c) we also measured secretion in the presence or absence of clotrimazole, an inhibitor of $\mathrm{Ca}^{2+}$-activated $\mathrm{K}^{+}$channels (Figure 7). In unstimulated cells, $\left[\mathrm{Ca}^{2+}\right]_{\mathrm{i}}$ was $70-120 \mathrm{nM}$. SubP increased $\left[\mathrm{Ca}^{2+}\right]_{\mathrm{i}}$ in 31 of 39 cells from 5 subjects by $139 \pm 33 \mathrm{nM}$ (peak value). All 39 cells responded to carbachol with increases in $\left[\mathrm{Ca}^{2+}\right]_{\mathrm{i}}$ that were larger than those to SubP; the responses to 1 and $10 \mu \mathrm{M}$ carbachol were $187 \pm 19 \mathrm{nM}$ and $253 \pm 17 \mathrm{nM}$, respectively (Figure 7B). We considered the possibility that gland cells that are unresponsive to SubP might be a different cell type. To help differentiate serous and mucous cells in the dispersed cell preparations, we used periodic acid-Schiff (PAS) staining and observed a negative correlation between PAS reactivity and SubP responsiveness. For SubP-responsive cells, 9 of 31 (29\%) were PAS positive (contain mucus), while for SubP-nonresponsive cells, 6 of $8(75 \%)$ were PAS positive. This difference is significant $(P<0.05$, Fisher's exact test). Consistent with these measurements, in experiments with intact glands, BAPTA-AM $(500 \mu \mathrm{M})$ reduced gland secretion stimulated by SubP by approximately $90 \%$ (Figure 7C) and clotrimazole $(25 \mu \mathrm{M})$ reduced gland secretion stimulated by SubP by approximately $80 \%$ (Figure 7D). Although the number of experiments was small for each of these 3 types of experiments,

\section{Figure 3}

Secretion rates of human airway glands to SubP. (A) Approximate doseresponse relationship for submucosal gland secretion from $\mathrm{HN}$ glands. Each point is the average of $10-14$ glands from 2-3 different HN subjects; $5 \mathrm{HN}$ subjects were used for the graph, and all data were obtained within 8 hours of harvest. The secretion rate was averaged over the first 15 minutes following SubP addition. Up to 3 increasing concentrations were administered per subject. (B and $\mathbf{C}$ ) Summary data for average secretion rates measured 15 minutes after $10 \mu \mathrm{M}$ SubP and 5-10 minutes after $10 \mu \mathrm{M}$ carbachol. The scale for responses to carbachol is 10 times the scale for responses to SubP. Bars in B show the secretion rate for responding glands and are labeled with the number of subjects, number of responding glands, and total number of glands tested. Five CF glands responded to SubP of more than 100 tested. The CF secretory rate for the 5 responding glands was significantly less than that for either $\mathrm{HN}$ or $\mathrm{DC}$ glands. ${ }^{*} P<0.05$. Bars in $\mathbf{C}$ show the secretion rate for responding glands and are labeled with the number of subjects and total number of glands tested. Error bars are SEM $(\mathbf{A}-\mathbf{C})$. they mutually reinforced the interpretation that SubP elevates $\left[\mathrm{Ca}^{2+}\right]_{\mathrm{i}}$ and opens $\mathrm{K}^{+}$channels.

Pig glands responded more robustly than buman glands to SubP. As previously reported $(26,30)$, porcine submucosal glands respond robustly to SubP, with $1 \mu \mathrm{M}$ SubP producing gland secretory rates equivalent to those produced by $100 \mu \mathrm{M}$ carbachol (26). However, in our experiments with humans, we observed much smaller responses to SubP than to carbachol (e.g., Figure 2A). To determine whether there is a genuine species difference as opposed to some difference between our procedures and those used previously (26), we directly compared secretory rates of individual glands stimulated with carbachol or SubP in humans and pigs. The secretory rates of single submucosal glands in pigs and humans exposed to $10 \mu \mathrm{M}$ carbachol were similar (data not shown), but secretory rates of glands exposed to $10 \mu \mathrm{M}$ SubP were more than 10 times higher in pigs than in humans. In tissues tested less than 7 hours from harvest, humans glands had a mean secretion rate of $0.29 \pm 0.05 \mathrm{nl} / \mathrm{min} /$ gland $(n=8$; 60 glands) compared with a mean secretion rate in pigs of $4.02 \pm 1.5$ $\mathrm{nl} / \mathrm{min} /$ gland ( $n=3 ; 28$ glands; $P<0.001$; Figure 8 ).

Features of gland responses to SubP studied with DIC microscopy. To determine the effects of SubP on cells within the glands, single

\section{Table 1}

Subject characteristics for individual gland secretion rate experiments

\begin{tabular}{lccc}
\hline & HN subjects & DC subjects & CF subjects \\
No. of subjects & 32 & 21 & 12 \\
Male, no. $(\%)$ & $21(67 \%)^{\mathrm{A}}$ & $6(30 \%)^{\mathrm{A}}$ & $5(41 \%)^{\mathrm{A}}$ \\
Age (mean $\pm \mathrm{SD})$ & $34 \pm 14^{\mathrm{A}}$ & $52 \pm 12$ & $27 \pm 9$ \\
\hline
\end{tabular}

\footnotetext{
AAge/gender not retrieved for 1 subject.
} 

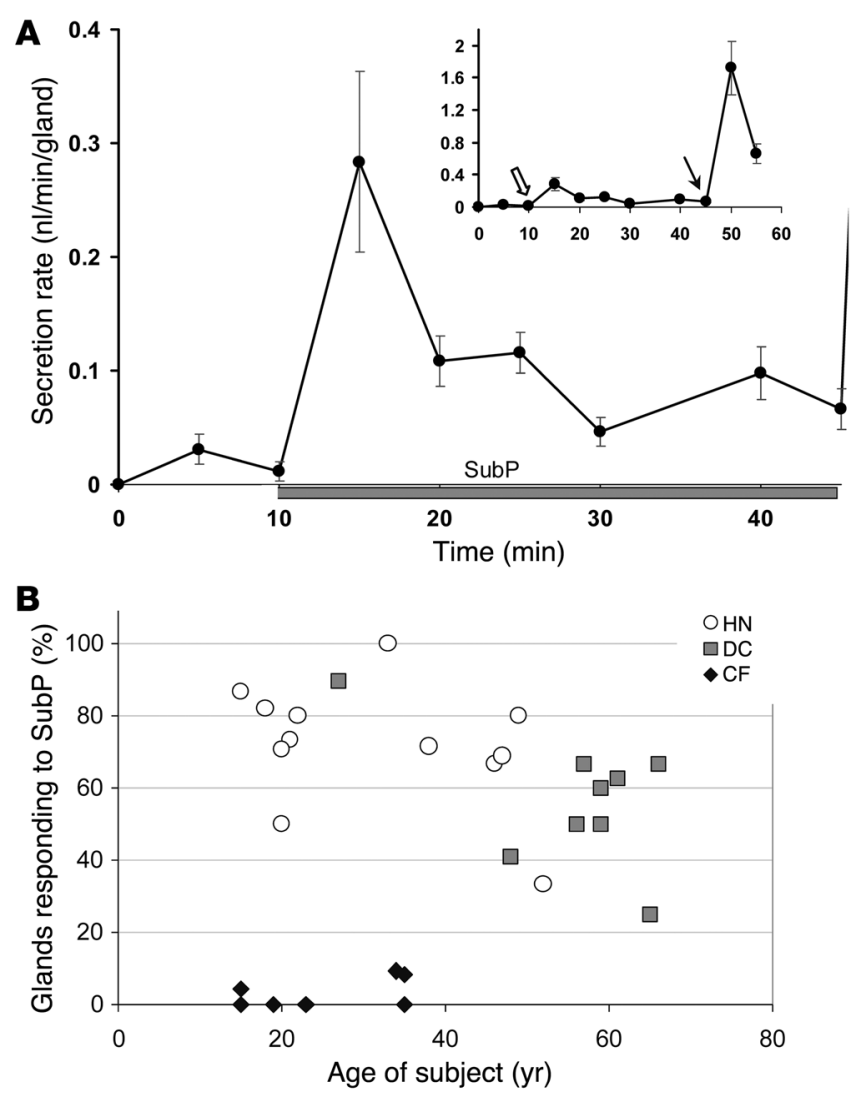

submucosal glands were microdissected from airway mucosa and mounted as described in the methods section for observation with DIC optics, using time-lapse digital imaging. Under our typical conditions ( $\times 40$ water immersion lens), the field usually contained only 1 or 2 serous acini or mucous tubules out of the more than 100 that make up a gland (ref. 36 and see below). Responses of tubules or acini were monitored quantitatively by measuring changes in the outer diameters and lumens of the tubules and acini, which reflect cell volume changes, as well as qualitatively by observing movement of particles in the mucus when visible. Responses of HN and DC subjects were similar and were combined for comparison with CF glands. When SubP $(1-10 \mu \mathrm{M})$ was superfused over the glands, we observed rapid shrinkage of acinar serous cells by $15 \%-50 \%$ of their height and $6 \%$ of their calculated volume, with an associated increase in lumen volume. Mucous cells in tubules from control subjects did not change volume significantly (increase of $2 \% \pm 5 \%$; $n=4$ ), although the response was quite variable (range, increase of $17 \%$ to decrease of $7 \%$ calculated cell volume change).

The mean peak change in normalized cell height was $26 \% \pm 14 \%$ for 7 control subjects (3 DC and 4 HN subjects) where clear images

\section{Figure 5}

Secretion rate to SubP is positively correlated to secretion rate to carbachol. Each point shows the peak single gland secretion rates to carbachol and SubP from 21 glands from $4 \mathrm{HN}$ subjects and 13 glands from 3 DC subjects. One symbol is used for both groups, because their rates did not differ. SubP stimulation preceded carbachol. Of 110 glands, $18(16 \%)$ responded only to carbachol; the mean peak secretion rate of those glands was $1.26 \pm 0.18 \mathrm{nl} / \mathrm{min} /$ gland. The solid line shows linear regression $(r=0.76, P<0.0001)$.

\section{Figure 4}

Typical gland response to SubP. (A) The time course of secretion rate to SubP shows an early peak like the response to carbachol. The graph shows (mean \pm SEM) secretion rates averaged over 5 -minute periods for 15 glands from $3 \mathrm{HN}$ subjects tested 6-9 hours from harvest; $10 \mu \mathrm{M}$ SubP plus $1 \mu \mathrm{M}$ phosphoramidon was added at 10 minutes. The inset is rescaled to show, in these same glands, both the response to SubP (open arrow) and the subsequent response to $10 \mu \mathrm{M}$ carbachol, added at the 45-minute time point (arrow). (B) Age- and disease-related changes in responses of human airway glands to SubP in HN, DC, and CF subjects. Each symbol shows the percentage of glands that responded to SubP as a function of type and age of subject. Data are for a subset of subjects, in which counts were made of total glands responding to carbachol.

were obtained following exposure to SubP. (The mean cell heights in control cells before application of SubP were serous, $21.2 \pm 2.0$ $\mu \mathrm{m}$ and mucous, $20.6 \pm 2.7 \mu \mathrm{m}$.) We also observed the following features: (a) increased flow of mucus from the serous acini and in tubules and ducts, as evident by the movement of particles within the mucus; (b) small and transient myoepithelial cell contractions; (c) persistence of these effects in the presence of $1 \mu \mathrm{M}$ atropine (which abolished the response to $1 \mu \mathrm{M}$ carbachol; data not shown). Examples of responses in $1 \mathrm{HN}$ and $1 \mathrm{DC}$ gland are shown in Figures 9 and 10, in which the increase in lumen volumes is plotted. Twelve glands from eleven control subjects were studied, and all responded to 1 or $10 \mu \mathrm{M}$ SubP except for 1 gland from a 56-yearold patient with chronic obstructive pulmonary disease (COPD).

In contrast with the reliable and stable acinar cell volume loss and lumen expansion observed in airway glands from control subjects in response to SubP, the gland cells in 3 of 4 CF subjects showed what appeared to be transient or sustained expansion of cell height by $5 \%-15 \%$ and a concomitant decrease of lumen volume (Figure 10, A-C). However, as described in Methods, when linear changes in the 2-dimensional optical slices were used to model volume changes in the 3 -dimensional tubules of the glands, the apparent "reversed" responses of the CF glands to SubP were seen to arise from the combination of a smaller, slower, and transient loss of cell volume and a superimposed transient contraction of the myoepithelial cells, resulting in lumen closure (Figure 11). The gland from 1 CF subject (CF48, who also responded when tested with the oil layer method; Supplemental Figure 1) responded to SubP with cells shrinkage, lumen expansion, and mucus flow from

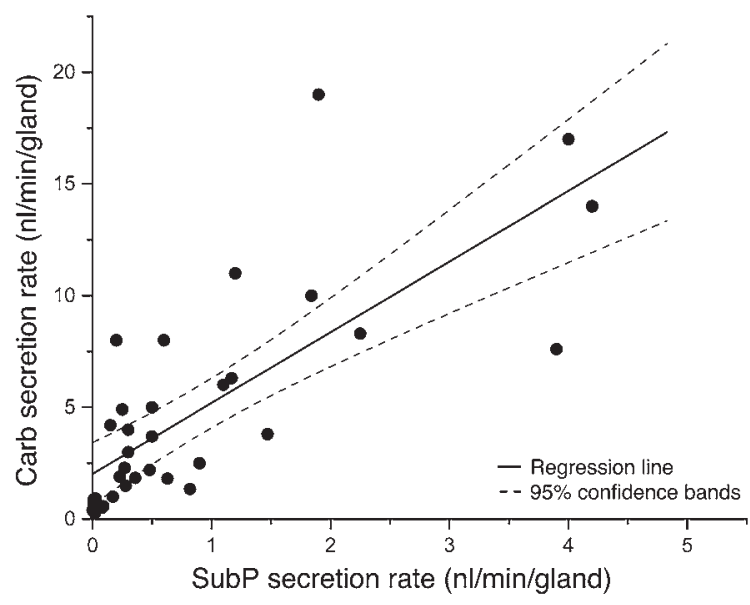



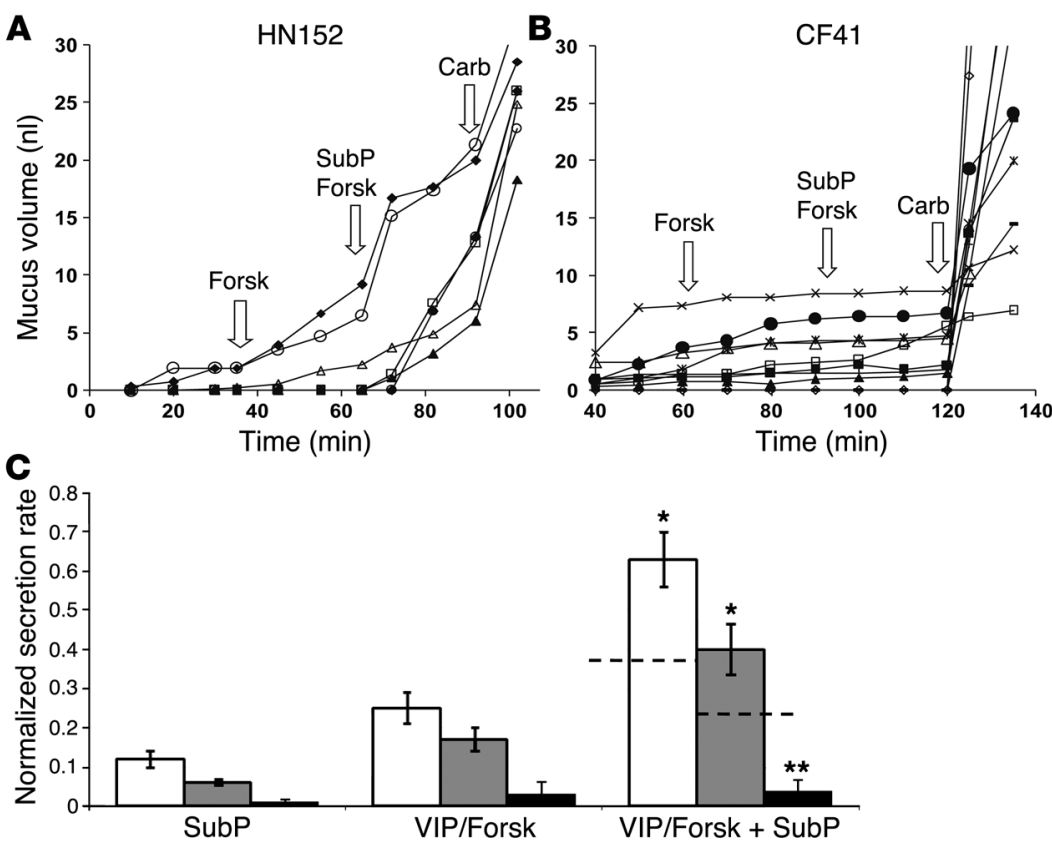

the acinus, but unlike control glands, this response was transient in the continued presence of SubP (Figure 11, D-F).

The DIC results help clarify our finding that many glands were "nonresponsive" to SubP when we measured mucus secretion with the bubble method. All human airway glands that we tested responded to SubP, but in some glands, the stimulated secretion rates are not sufficient to result in measurable flow of mucus from the gland duct opening. This may occur because of physical capacitance within the glands (i.e., lumen dilation without mucus exit), which could be exacerbated if there is a mismatch between fluid and macromolecular secretion, leading to higher viscosity.

For time-lapse sequences for selected control and CF gland responses to SubP, see Supplemental Videos 1-3.

\section{Discussion}

The present results in humans and prior results in mice (18, 31 ) establish that mucosal chili oil activates airway submucosal glands, at least in part via a pathway that releases SubP, and that in these 2 species, SubP stimulates the glands by a CFTR-dependent mechanism. In humans, SubP must work by at least one pathway that is not involved with the elevation of cAMP, because when SubP is added to saturating concentrations of forskolin, it produces a synergistic increase in secretion. One possible mechanism for such synergy would be elevation of $\left[\mathrm{Ca}^{2+}\right]_{\mathrm{i}}$ by SubP and subsequent activation of basolateral $\mathrm{Ca}^{2+}$-activated $\mathrm{K}^{+}$channels, as suggested by the data in Figure 7. The small secretory response to SubP, its near-total dependence upon CFTR, and its synergy with forskolin suggest that, unlike carbachol, it does not activate apical $\mathrm{Ca}^{2+}$-activated $\mathrm{Cl}^{-}$channels. We do not know how this occurs, but it also occurred in previous synergy experiments with low-dose carbachol (19). Possible reasons for this are that the elevation of $\left[\mathrm{Ca}^{2+}\right]_{\mathrm{i}}$ is subthreshold for $\mathrm{Ca}^{2+}$-activated $\mathrm{Cl}^{-}$channels and that the $\left[\mathrm{Ca}^{2+}\right]_{\mathrm{i}}$ elevation is spatially restricted in the cells. The experiments measuring $\left[\mathrm{Ca}^{2+}\right]_{i}$ with Fura-2 support the first interpretation.

Activation of CFTR-dependent secretion by classical $\left[\mathrm{Ca}^{2+}\right]_{i}$ elevating agents like ACh also occurs in the intestine, in which

\section{Figure 6}

Stimulation of secretion by SubP is synergistic with forskolin or VIP in HN and DC but not CF glands. (A) Secretion from individual $\mathrm{HN}$ glands to $10 \mu \mathrm{M}$ forskolin (forsk), $10 \mu \mathrm{M}$ SubP plus forskolin, and finally $10 \mu \mathrm{M}$ carbachol. (B) The same sequence in a CF subject except for a 1-hour interval of basal secretion (data not shown). (C) Summary showing synergism in control subjects for saturating concentrations of SubP (averaged over 15 minutes), with saturating concentrations of either forskolin or VIP (averaged over 20-30 minutes). Responses were normalized to the peak secretory rates of those same glands to $10 \mu \mathrm{M}$ carbachol given at the end of the experiment. Responses to forskolin plus SubP in HN (white bars) or DC (gray bars) subjects were greater than the summed responses of the agents given separately (indicated by the dashed lines; ${ }^{*} P<0.05$ ). In contrast, CF glands (black bars) showed minimal responses to either agent alone or in combination; $\left({ }^{* *} P<0.01\right.$ versus control groups). Experiments were based on 20-45 glands from $4 \mathrm{HN}, 6 \mathrm{DC}$, and 3 CF subjects. Error bars are SEM.
$\mathrm{Cl}^{-}$secretion stimulated by ACh is completely lost in CF (37-39). In the intestine, $\mathrm{Cl}^{-}$secretion stimulated by $\mathrm{Ca}^{2+}$-elevating agents depends upon the elevation of $[\mathrm{cAMP}]_{\mathrm{i}}$, secondary to prostaglandin release, because it can be blocked with indomethacin in human (40) or mouse colon (41) and it is strongly synergistic with $\mathrm{PGE}_{2}$ in the guinea pig colon (42). In airway submucosal glands, it is also possible that SubP induces an elevation of $[\mathrm{cAMP}]_{\mathrm{i}}$ in gland cells, but we have no direct evidence of this.

In the intestine, the CFTR dependence of $\mathrm{Ca}^{2+}$-mediated secretion can be observed clearly, because the intestinal cells typically lack $\mathrm{Ca}^{2+}$-activated $\mathrm{Cl}^{-}$channels (43). However, human and mouse airway submucosal glands certainly contain $\mathrm{Ca}^{2+}$-activated $\mathrm{Cl}^{-}$channels. Carbachol has been shown to elevate $\left[\mathrm{Ca}^{2+}\right]_{\mathrm{i}}$ in mouse nasal gland acinar cells (28), and bumetanide-sensitive and niflumic acid-sensitive fluid secretion in response to carbachol is robust in CF human glands (present results and ref. 7) and in CF mouse glands (18), yet SubP, unlike carbachol, failed to activate these channels (or activated them only weakly; see below).

The hypothesis that SubP stimulates serous cell fluid secretion by activating basolateral $\mathrm{Ca}^{2+}$-activated $\mathrm{K}^{+}$channels but not apical $\mathrm{Ca}^{2+}$-activated anion channels is the same hypothesis put forth to explain CFTR-dependent synergy between low levels of cholinergic and VIP stimulation (19). Thus, SubP, which by itself is a much weaker secretagogue in human and mouse glands than carbachol, appears to produce effects similar to those of low concentrations of carbachol. This hypothesis might account for the rare secretory responses of human CF glands to SubP: in some glands the $\mathrm{Ca}^{2+}$ signal might be strong enough to activate some apical $\mathrm{Ca}^{2+}$-activated anion channels. Regardless of the cellular mechanism, the main point of our experiments is that SubP-mediated fluid secretion from human airway glands is CFTR dependent and is synergistic with VIP or forskolin.

Distinguishing types of gland secretion. When considering mucus secretion by submucosal glands, it is important to distinguish at least the following 3 components that make up bulk mucus: mucin secretion, non-mucin protein secretion, and electrolyte-driven fluid 
A

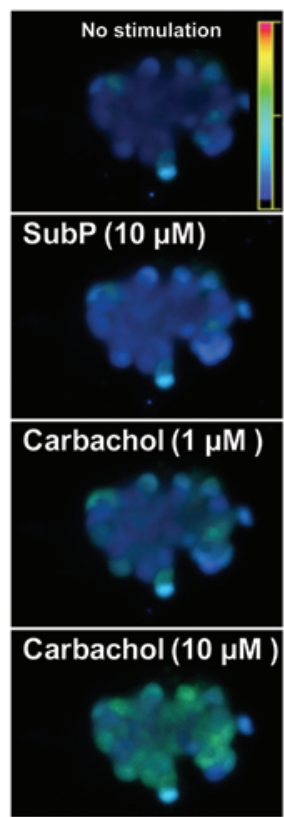

\section{B 300}
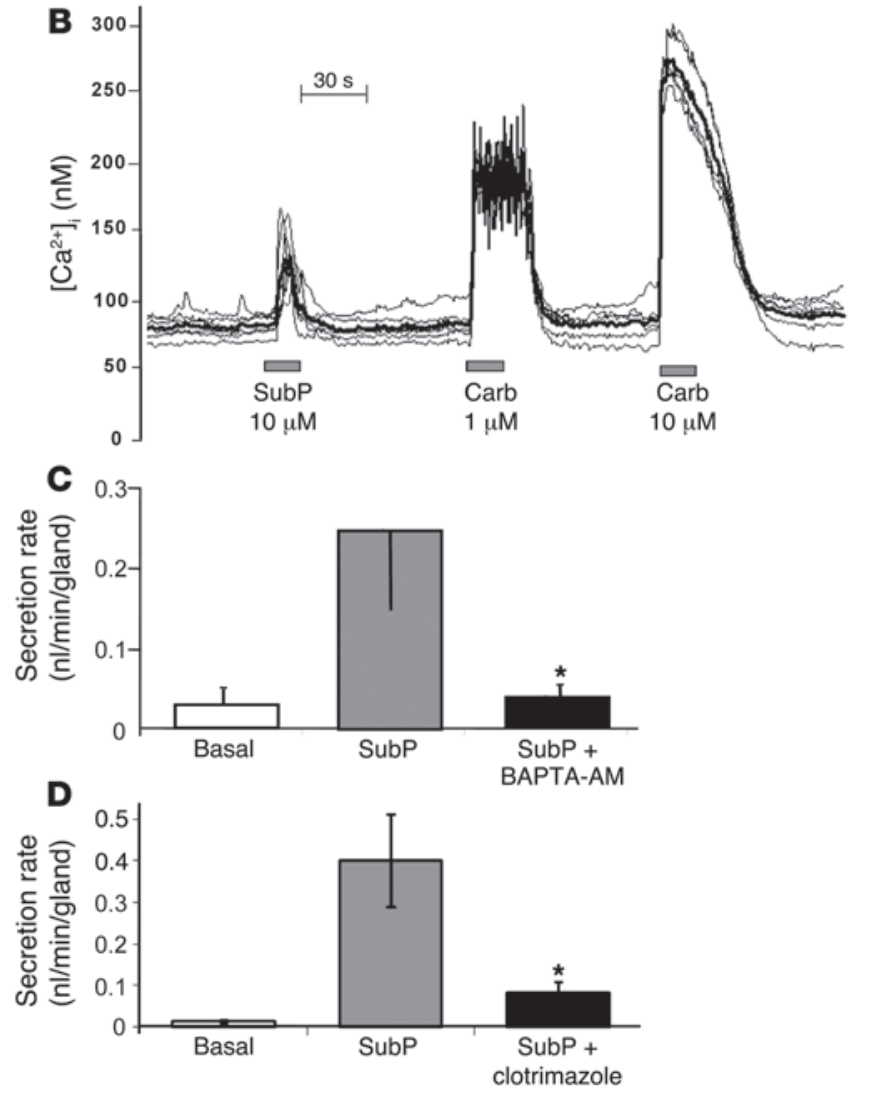

Figure 7

Evidence that SubP stimulates gland secretion, in part, via elevating $\left[\mathrm{Ca}^{2+}\right]_{\text {i. }}$ (A) Fluorescence changes in response to $10 \mu \mathrm{M}$ SubP and 1 or $10 \mu \mathrm{M}$ carbachol. Cell diameters in images are approximately 20 microns. (B) $\left[\mathrm{Ca}^{2+}\right]_{\mathrm{i}}$ versus time for 6 cells from images in A, measured in response to sequential pulses of $10 \mu \mathrm{M}$ SubP and 1 and $10 \mu \mathrm{M}$ carbachol. Fluorescence ratio, $340 \mathrm{~nm} / 380 \mathrm{~nm}$. (C) Mean response to SubP in presence or absence of BAPTA-AM $(500 \mu \mathrm{M})$; 4 experiments from $2 \mathrm{HN}$ and $1 \mathrm{DC}$ subjects (16-20 glands). Error bars are SEM. (D) Mean response to SubP in the absence and presence of clotrimazole $(25 \mu \mathrm{M})$, which blocks $\mathrm{Ca}^{2+}$-activated $\mathrm{K}^{+}$channels ( $n=4,27-42$ glands). ${ }^{*} P<0.05$ versus SubP responses. Error bars are SEM. secretion. The bubble method used here measures total mucus volume, which is primarily water. This contrasts with most early studies of airway gland secretion that relied solely on markers of macromolecular secretion. Thus, Rogers et al. measured fucose, hexose, and proteins in the apical fluid of Ussing chambers as biochemical markers of mucus secretion from bronchial explants from CF and non-CF tissues (44). They found similar amounts of markers in the basal state. However, after stimulation with methacholine, terbutaline, or SubP, they observed large increases for each marker in control tissues, but in CF tissues, the increases were significantly smaller for all 3 agonists. As they recognized, the reduced levels of macromolecular components in the apical fluid is consistent either with fewer macromolecules being secreted or with CF mucus being "more viscid than normal and ... less easily collected" (44). Much evidence now favors the latter interpretation. The loss of CFTR inhibits anion-mediated fluid secretion, so that the normally rapid and extensive expansion of mucin granules is slowed and constrained, leading to a more densely entangled and hence more viscous network (5). Impacted secretions with high solids and viscosity were produced in pig airway glands by inhibiting anion transporters (14-16), and undispersed Paneth cell granules

\section{Figure 8}

SubP stimulates airway gland secretion more strongly in pigs than in humans. A graph of (mean \pm SEM) single gland secretion rates for 15 minutes after $10 \mu \mathrm{M}$ SubP application is shown $(n=3$ pigs, 28 glands; $n=8$ humans, 60 glands). Time from harvest to testing was $4 \pm 2$ hours for pigs and $6 \pm 2$ hours for humans. ${ }^{\star \star *} P<0.001$. accumulate in the intestinal crypts of CFTR-knockout mice (45). In this regard, it was recently proposed that $\mathrm{HCO}_{3}{ }^{-}$plays a crucial role in enabling mucin granule expansion by competing away the charge shielding $\mathrm{Ca}^{2+}$ and $\mathrm{H}^{+}$ions that are required to compact mucins in granules. The known deficiency of $\mathrm{HCO}_{3}{ }^{-}$secretion in many CF organs could thus contribute to altered mucus properties (46). Thus, although our measurements indicate that the volume of carbachol-stimulated mucus is normal in CF, it arises from hypertrophied glands, and its properties may well be changed so that it is less easily cleared or collected (21-24, 47).

The present results illustrate the utility of combining DIC observations of cell responses in intact, isolated glands with measurements of volume secretion by individual glands. In DIC experiments, SubP caused HN or DC acinar serous cells to lose volume

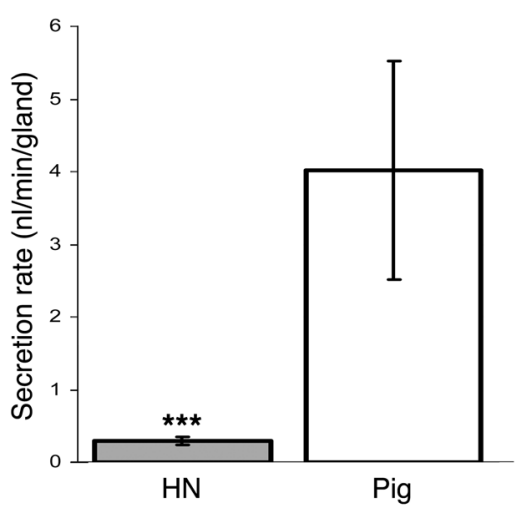



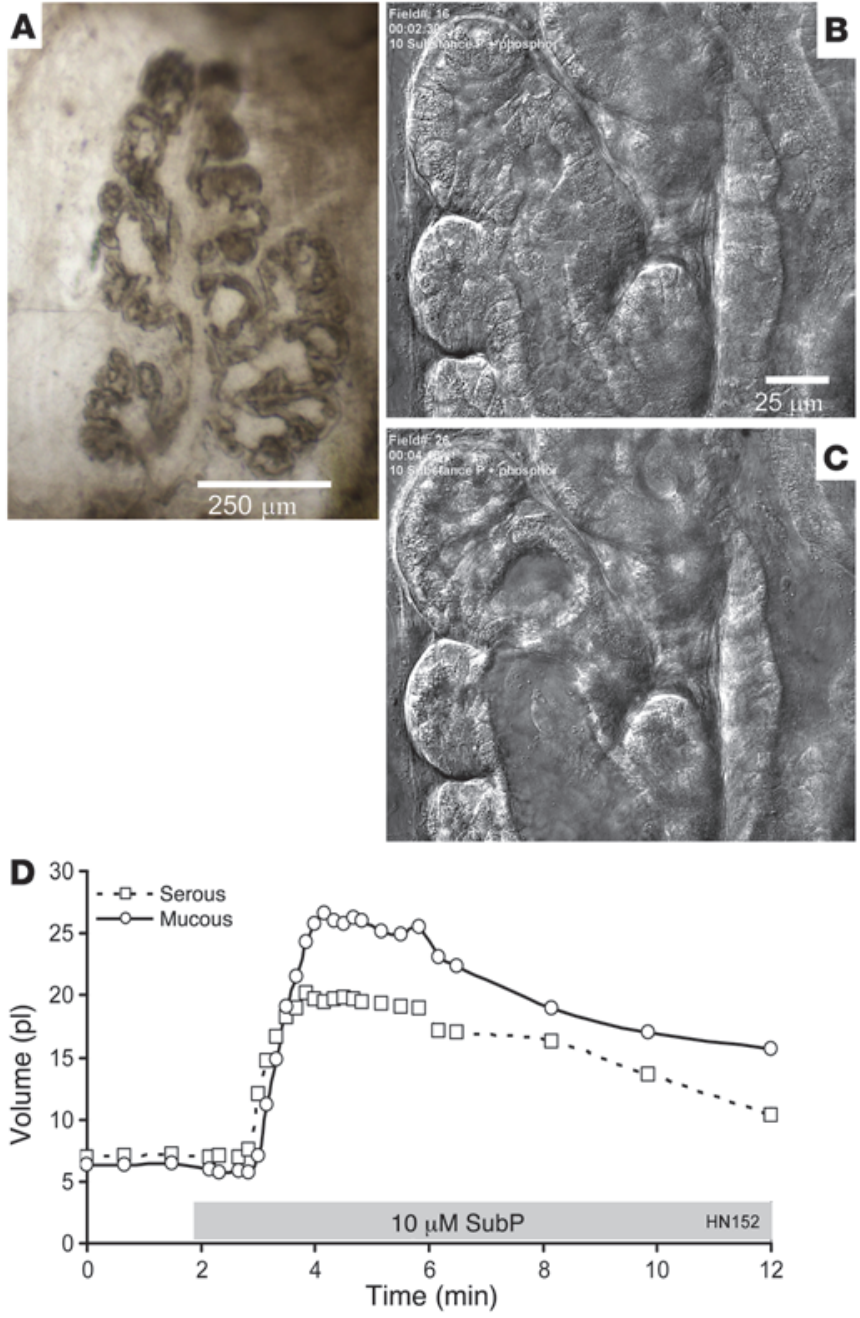

for as long as SubP was present, while, concomitantly, the gland lumens expanded and mucus flowed from the acini and along the tubules (see also ref. 4). The loss of cell volume coupled with lumen expansion and mucus flow is a marker of electrolyte-driven fluid

\section{Figure 9}

Isolated $\mathrm{HN}$ gland exposed to SubP shows cell shrinkage, lumen volume expansion, and fluid secretion when monitored with DIC. (A) One lobe of an isolated human gland. Scale bar: $250 \mu \mathrm{m}$. (B) Serous acini and mucous tubules just prior to stimulation. (C) Same gland structures 100 seconds after addition of $10 \mu \mathrm{M}$ SubP plus $1 \mu \mathrm{M}$ phosphoramidon. Scale bar: $25 \mu \mathrm{m}$ (B and $\mathbf{C})$. (D) Plots of volumes of serous and mucous lumens as a function of time and stimulation (indicated with gray bar; see Methods).

secretion (e.g., ref. 48). Myoepithelial cell contractions were small and transient, indicating that sustained or rhythmic contractions are not required for mucus secretion.

In CF glands, DIC markers of fluid secretion stimulated by SubP were absent in 3 of 4 subjects. Importantly, all CF glands responded transiently to SubP, proving that receptors are still present, but the transient cell volume loss was not accompanied by other markers of fluid secretion, and the brief myoepithelial contractions actually reduced the lumen volumes in the CF cells.

Species differences. We found that SubP was many fold more efficacious in pig versus human glands. In this regard, human glands were more like mouse glands than pig glands, because mouse glands also show a much smaller response to SubP than they do to carbachol $(18,31)$. The approximately 10 -fold increased efficacy of SubP for stimulating mucus secretion from pig versus human glands is consistent with a much greater density of mucosal SubP innervation in the pig bronchial mucosa, which has a profuse apical plexus of $1 \mu \mathrm{m}$ diameter axons $\left(\sim 2,000\right.$ terminations per $\mathrm{mm}^{2}$, $94 \%$ of which are immunoreactive for SubP) (49). Although a similarly dense neural plexus was observed in human bronchial tissues, SubP immunoreactivity was barely detectable in it (49).

We hypothesize that the density of SubP receptors is higher in pig glands than it is in human glands. If true, this could result in a larger increase in $\left[\mathrm{Ca}^{2+}\right]_{i}$ within the pig gland cells. This would be expected to increase secretion through active CFTR and also might be sufficient to recruit apical $\mathrm{Ca}^{2+}$-activated $\mathrm{Cl}^{-}$channels. If the latter is true, a larger component of SubP-mediated secretion may be spared in CFTR-knockout pigs than in CF humans. Whether this will have relevance for the development of airway disease in the CFTR-knockout pig can now be tested directly $(50,51)$. This species difference is the largest we have yet observed between humans and
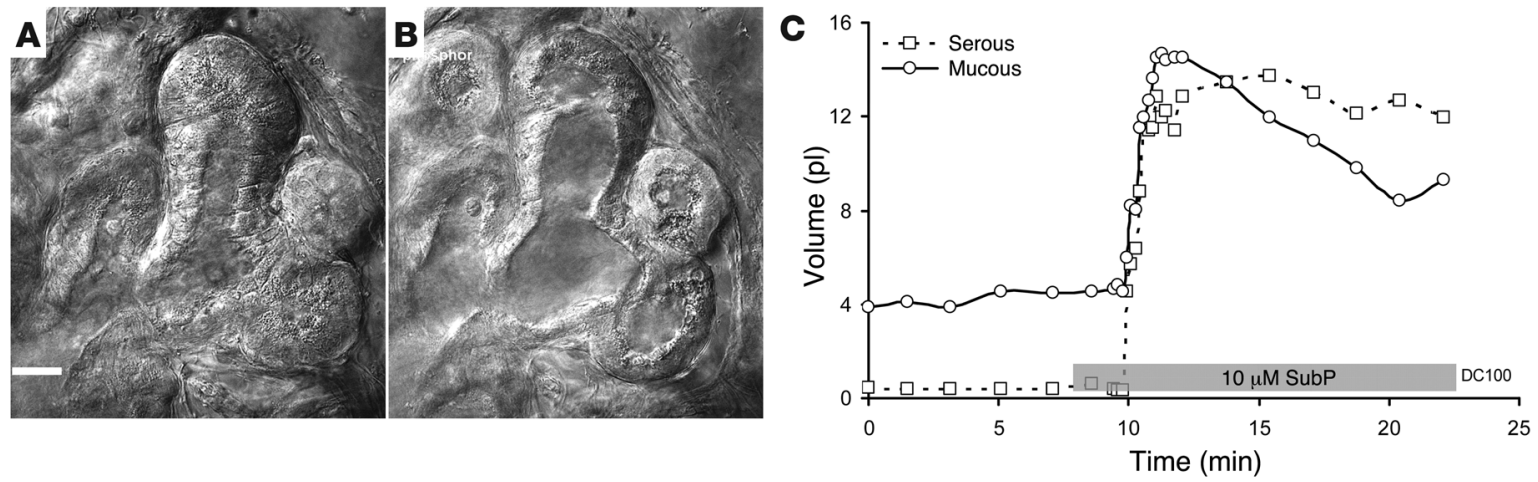

Figure 10

Isolated DC gland exposed to SubP shows cell shrinkage, lumen volume expansion, and fluid secretion when monitored with DIC. The gland is from a subject with COPD. (A) Serous acini and mucus tubules just prior to stimulation. (B) The same structures at peak of response to $10 \mu M$ SubP plus $1 \mu \mathrm{M}$ phosphoramidon (phosphor). Scale bar: $20 \mu \mathrm{m}$ (A and B). (C) Plots of volumes of serous and mucous lumens as a function of time and stimulation (indicated with gray bar; see Methods). 

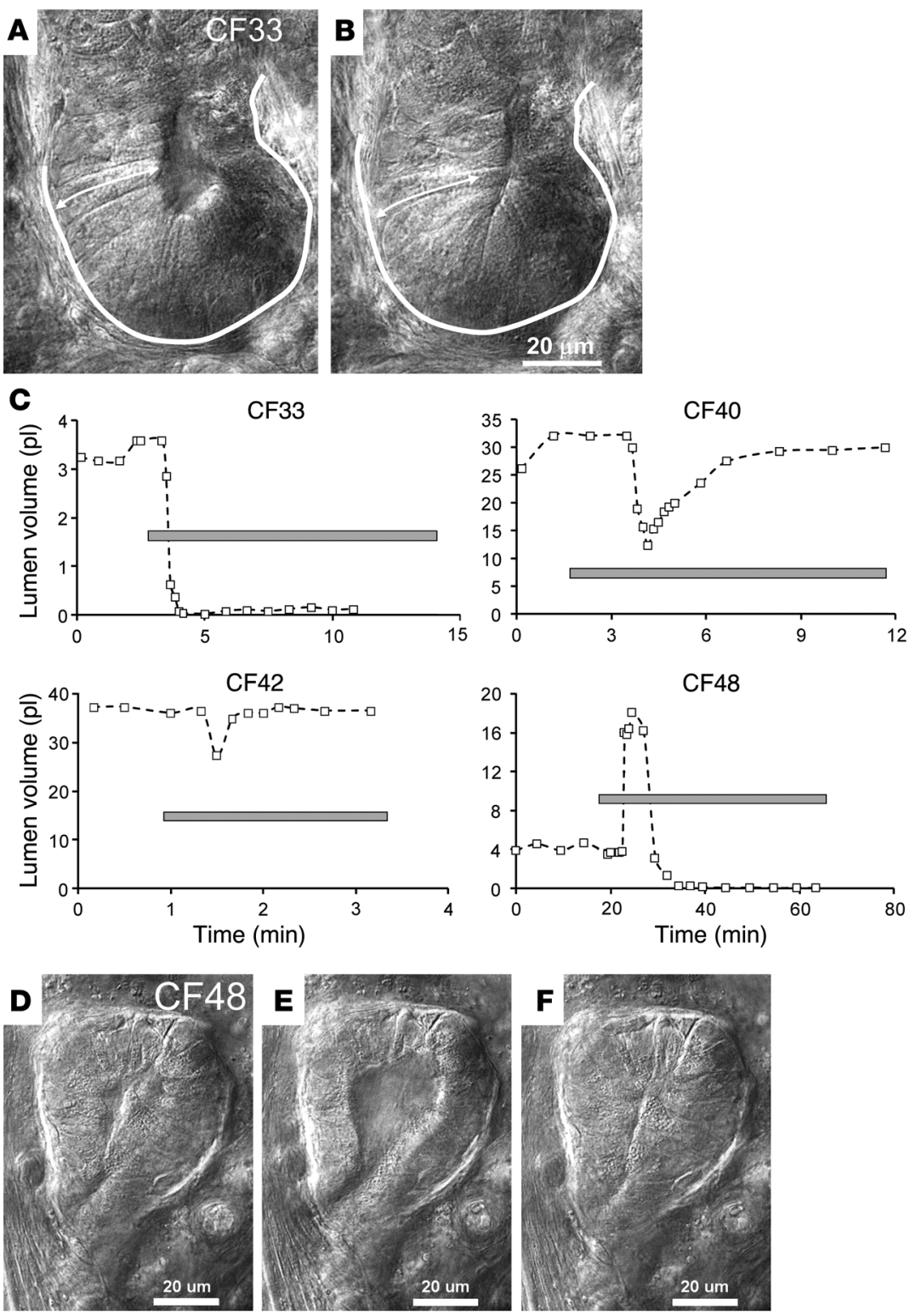

\section{Figure 11}

Aberrant responses in CF gland acini to SubP. (A) Acinus and tubule just prior to stimulation. (B) Same structures at peak response to $10 \mu \mathrm{M}$ SubP plus $1 \mu \mathrm{M}$ phosphoramidon. The acinus was outlined and an arrow was drawn spanning cell height in the control state, and these were then copied onto the image of the acinus at peak stimulation to show changes. (C) Plots of lumen volumes assuming them to be cylinders (see Methods) for 4 CF subjects stimulated with SubP. A decrease in lumen volume was observed in 3 of 4 CF subjects stimulated with SubP; these subjects did not secrete mucus when assayed with oil layer method. CF48 responded with a normal increase in lumen volume but with a much shorter time course than controls. The gray bar indicates the period of SubP stimulation. (D-F) Lumen expansion of CF48. Images are just before (D), at peak (E), and at minimal lumen volume $(F)$ (which was maintained in this gland) in response to $10 \mu \mathrm{M}$ SubP plus $1 \mu \mathrm{M}$ phosphoramidon and $10 \mu \mathrm{M}$ atropine. Scale bar: $20 \mu \mathrm{m}$. pig airway glands and is under further investigation (M. Khansaheb, unpublished observations). However, even more dramatic differences have been described for SubP effects in pigs and humans: application of SubP to the iris sphincter muscle of pigs increased inositol triphosphate $\left(\mathrm{IP}_{3}\right)$ accumulation and contracted the muscle, while in humans, it did not increase $\mathrm{IP}_{3}$ or cause contractions but instead increased cAMP production (52).

Relevance to $\mathrm{CF}$ airway disease. The ability of mucosal irritants to evoke gland secretion in control but not CF tissues may be one reason that low levels of local pathogens are not quickly cleared from $\mathrm{CF}$ airways. The hypothesis that $\mathrm{CF}$ airway infections are related to abnormal mucus properties and clearance is increasingly attractive (reviewed in refs. 5, 9, 53). Because most upper airway mucus arises from glands, it is critical to define the role of CFTR in mucus secretion by airway glands. The present study shows that SubP, like VIP, activates secretion via a process that is mainly CFTR dependent, and yet, the 2 agonists are synergistic and their combined effects are also CFTR dependent. We remain ignorant of how these processes are employed in normal airways. Normal breathing in quiescent animals produces a level of neural tone in airway parasympathetic nerves, (54) and we speculate that glands are stimulated at low levels by such input. Our prior results show that CFTR plays a proportionately larger role during low levels of gland fluid secretion (19). The present results reinforce that conclusion, and may also be interpreted to suggest that local irritants, acting through axonal reflex rather than central reflex pathways, also stimulate CFTR-dependent gland secretion. If this reasoning is correct, then hyposecretion of anion-mediated fluid by CF airway glands, both in the "basal" state and in response to minor local irritants, would be expected to hamper the initial formation of the mucus gel $(5,7$, 10-24, 46), thus limiting the normal dispersion of antimicrobialrich mucus over the airway surface and leading instead to accumulation within glands (14-16) and, via tethering to gland orifices, to mucus plugging of smaller airways. These consequences would be 


\section{Table 2}

Subject characteristics for isolated gland DIC measurements

\begin{tabular}{lccc} 
& HN subjects & DC subjects & CF subjects \\
No. of subjects & 7 & 4 & 4 \\
Male, no. $(\%)$ & $3(43 \%)$ & $1(25 \%)$ & $2(50 \%)$ \\
Age (mean \pm SD) & $34 \pm 16$ & $56 \pm 11$ & $29 \pm 9$ \\
\hline
\end{tabular}

expected to diminish the innate mucosal defenses of CF airways and set the stage for chronic infections.

\section{Methods}

Human airway preparations. These studies were approved by the Institutional Review Boards of Stanford University and Yonsei University. At Stanford University, human bronchial tissues were obtained, after prior written consent, immediately following lung transplants. Surgical scrap tissues were obtained from donor tracheae at Stanford University. At Yonsei University, tracheotomy flaps from subjects without lung disease were obtained after prior written consent.

Data were obtained from $32 \mathrm{HN}$ donor tracheae, $5 \mathrm{HN}$ tracheotomy flaps, 12 CF patients, and 21 DC patients, who had transplants for diseases other than CF. The HN donor tracheae were obtained at each transplant as surgical scrap (donor lungs are transplanted one at a time with anastomosis at the level of the mainstem bronchi). The $21 \mathrm{DC}$ lungs were from 10 patients with COPD, 4 patients with pulmonary fibrosis, 3 patients with primary pulmonary hypertension, 3 patients with interstitial lung disease (ILD) (1 patient with ILD/sarcoidosis, 1 patient with ILD/neurofibromatosis, and 1 patient with ILD/unknown), and 1 patient with idiopathic pulmonary hemosiderosis. Genotypes were available for 8 of the CF subjects; 5 were $\Delta \mathrm{F} 508$ homozygous, with 1 of each of the following: $\Delta$ F508/N1303K, G542X/W1282X, and 406-1 G->A/H119Y. Subject characteristics for gland secretion experiments are given in Table 1 and for DIC experiments are given in Table 2. One CF and two HN patients were studied only with DIC, all others were also used in gland secretion experiments. The DC subjects used for DIC comprised 3 COPD patients and 1 familial pulmonary fibrosis subject. Tissues used for measurements of $\left[\mathrm{Ca}^{2+}\right]_{\mathrm{i}}$ in acinar cells were tracheotomy flaps obtained from patients without pulmonary disease ( $n=5,53 \pm 18$ years).

All tissues were transported to the laboratory in cold Physiosol solution (Abbott Laboratories) and were then transferred to ice-cold Krebs-Ringer bicarbonate buffer (KRB), bubbled with $95 \% \mathrm{O}_{2}-5 \% \mathrm{CO}_{2}$, in which they were maintained until use, usually within 24 hours. The KRB composition was $115.0 \mathrm{mM} \mathrm{NaCl}, 2.4 \mathrm{mM} \mathrm{K}_{2} \mathrm{HPO}_{4}, 0.4 \mathrm{mM} \mathrm{KH}_{2} \mathrm{PO}_{4}, 25.0 \mathrm{mM}$ $\mathrm{NaHCO}_{3}, 1.2 \mathrm{mM} \mathrm{MgCl}_{2}, 1.2 \mathrm{mM} \mathrm{CaCl}, 10.0 \mathrm{mM}$ glucose, and $1.0 \mu \mathrm{M}$ indomethacin. KRB was made to $90 \%$ volume, and the osmolarity was measured with a Wescor 5500 Vapor Pressure Osmometer. Distilled water was added to adjust the osmolarity to $290 \pm 5 \mathrm{mOsm}$. The $\mathrm{pH}$ was verified to be 7.4 (Orion $420 \mathrm{~A} \mathrm{pH}$ meter) after bubbling with $95 \% \mathrm{O}_{2}-5 \% \mathrm{CO}_{2}$.

Pig tracheae. Pig tracheae were obtained from fresh carcasses of 3 Juvenile Yorkshire pigs of either sex, weighing $35 \sim 50 \mathrm{~kg}$, following acute experiments carried out for other purposes. Procedures for care and euthanization of pigs were approved by the Administrative Panel on Laboratory Animal Care (Stanford University's Institutional Animal Care and Use Committee); no pigs were sacrificed specifically for the present experiments.

Optical measurement of mucus secretion rates (mucus bubble method). To prepare tissues for optical recording of mucus secretion rates by individual glands, a piece of ventral trachea or bronchus of approximately $0.5 \mathrm{~cm}^{2}$ was pinned mucosal side up and the mucosa with underlying glands was dissected from the cartilage and mounted in a $35-\mathrm{mm}$ diameter, Sylgard, lined plastic Petri dish (Dow Corning Corporation), with the serosa in the bath $(\sim 1 \mathrm{ml}$ volume $)$ and the mucosa in air. The tissue chamber was maintained at $35^{\circ} \mathrm{C}-37^{\circ} \mathrm{C}$ and high humidity, using either a Sensortek S-4 Peltier effect TC-102 Temperature Controller and Fisher-Milligan Gas Washer or a thermistor-controlled LU-CB1 warming chamber and humidifier (Medical Systems Corp.). The tissue surface was cleaned and blotted dry with cotton swabs and further dried with a stream of gas, after which 20-30 $\mu \mathrm{l}$ of water-saturated mineral oil was placed on the surface. The tissue was warmed to $37^{\circ} \mathrm{C}$ at a rate of approximately $1.5^{\circ} \mathrm{C} \mathrm{min}-1$ and continuously superfused with warmed, humidified $95 \% \mathrm{O}_{2}-5 \% \mathrm{CO}_{2}$. Pharmacological agents were diluted to final concentration with warmed, gassed bath solution and were added to the serosal side by complete bath replacement. Bubbles of mucus within the oil layer were visualized by oblique illumination and digital images were captured either with the macro mode of a Nikon digital camera or by mating a digital camera to 1 ocular of a Wild stereomicroscope. Each image contained an internal reference grid to compensate for any minor adjustments in magnification made during the experiment. Stored images were analyzed either by direct measurement or with ImageJ software (http://rsb.info.nih.gov/ij/). Mucous volumes were determined from the size of the spherical bubbles; bubbles that were not approximately spherical were omitted from secretion rate analyses and are given as $\mathrm{nl} / \mathrm{min} /$ gland. Details of these methods are given in ref. 33 .

Secretion rates for individual glands vary over a many fold range. For synergy experiments, variations in gland secretion rates to forskolin, SubP, and the combination were minimized by normalizing the rates to the peak secretion rates for carbachol in those same glands tested at the end of the experiment.

Estimating the proportion of responding glands. In past experiments, we found carbachol to be the most efficacious agonist for stimulating mucus secretion of those we tried with human glands, and at high $(10 \mu \mathrm{M})$ concentrations, carbachol continued to stimulate secretion in CF glands. Therefore, we used responsiveness to a 5-minute exposure to $10 \mu \mathrm{M}$ carbachol at the end of experiments to estimate the number of viable glands in each preparation; the number of glands responding to SubP was then divided by the number responding to carbachol to estimate the proportion of SubP-responsive glands.

Fura-2 measures of $\left[\mathrm{Ca}^{2+}\right]_{i}$. Tracheal submucosal glands were isolated using a Wild zoom binocular dissecting microscope and transferred to $2 \mathrm{ml}$ of bicarbonate-buffered Ringer's solution (125.0 mM NaCl, $0.4 \mathrm{mM} \mathrm{KH}_{2} \mathrm{PO}_{4}$, $1.6 \mathrm{mM} \mathrm{K}_{2} \mathrm{HPO}_{4} \cdot 3 \mathrm{H}_{2} \mathrm{O}, 1.0 \mathrm{mM} \mathrm{MgCl} 2,5.0 \mathrm{mM}$ glucose, $10.0 \mathrm{mM} \mathrm{Na}$-acetate, $2.0 \mathrm{mM}$ glycine, $1.0 \mathrm{mM} \alpha$-ketoglutarate, $2.0 \mathrm{mM} \mathrm{CaCl}_{2}, 25.0 \mathrm{mM}$ $\mathrm{NaHCO}_{3}$ ) gassed with $95 \% \mathrm{O}_{2} / 5 \% \mathrm{CO}_{2}$. After 7 minutes of incubation in this buffer solution, containing $2 \mathrm{mg} / \mathrm{ml}$ of Collagenase NB 4 Standard Grade (SERVA) and $2 \mathrm{mg} / \mathrm{ml}$ of Trypsin Inhibitor (Sigma-Aldrich) at $37^{\circ} \mathrm{C}$, submucosal glands were agitated gently using a fire-polished, wide-bore (1-2 mm) Pasteur pipette. After sedimentation the gland cells were washed twice with enzyme-free bicarbonate-buffered Ringer's solution. The isolated acinar fragments were seeded onto glass cover slips $(22 \times 22 \mathrm{~mm})$ coated with poly-L-lysine and were incubated for 30 minutes in physiologic salt solution ( $140 \mathrm{mM} \mathrm{NaCl}, 5 \mathrm{mM} \mathrm{KCl}, 1 \mathrm{mM} \mathrm{MgCl}, 1 \mathrm{mM} \mathrm{CaCl}_{2}$, $10 \mathrm{mM}$ HEPES, and $10 \mathrm{mM}$ glucose), containing $5 \mu \mathrm{M}$ fura-2, AM (Teflabs) in the presence of Pluronic F-127 (Invitrogen) to enhance dye loading. Fura-2-loaded cells were mounted in a flow chamber on the stage of an inverted microscope (Nikon) for imaging; temperature was maintained at $37^{\circ} \mathrm{C}$. The cells were illuminated at $340 \mathrm{~nm}$ and $380 \mathrm{~nm}$, and the emitted fluorescence at $510 \mathrm{~nm}$ was collected with a CCD camera and analyzed using the MetaFluor system (Universal Imaging). The fluorescence ratio $(340 \mathrm{~nm} / 380 \mathrm{~nm})$ was taken as the measure of $\left[\mathrm{Ca}^{2+}\right]_{\mathrm{i}}$ and fluorescence images were obtained at 2 second intervals. 
$\left[\mathrm{Ca}^{2+}\right]_{\mathrm{i}}$ was calculated by using following equation $(55):\left[\mathrm{Ca}^{2+}\right]_{\mathrm{i}}=K_{d}\left[\left(R-R_{\min }\right) /\right.$ $\left.\left(R_{\max }-R\right)\right] \beta$, where $K_{d}$ is the dissociation constant of fura- 2 for $\mathrm{Ca}^{2+}(224 \mathrm{nM}$ at $\left.37^{\circ} \mathrm{C}\right), r$ is the ratio of fluorescence of the sample at 340 and $380 \mathrm{~nm}, R_{\max }$ represents the saturated $\mathrm{Ca}^{2+}$ level determined by addition of $10^{-5} \mathrm{M}$ ionomycin, $R_{\min }$ represents the free $\mathrm{Ca}^{2+}$ level controlled by $5 \mathrm{mM}$ EGTA, and $\beta$ represents the ratio of fluorescence at $380 \mathrm{nM}$ in no $\mathrm{Ca}^{2+}$ and saturating $\mathrm{Ca}^{2+}$.

DIC imaging of isolated airway submucosal glands. Tissues containing glands were isolated as described above and then were further microdissected to prepare relatively clean but intact glands for optimal imaging. When judged suitable for imaging, the glands were transferred to microperfusion chambers on the stage of an upright Nikon Eclipse E600FN Series Microscope equipped with DIC and epifluorescence. They were continuously perfused with $\mathrm{Krebs}$, gassed with $95 \% \mathrm{O}_{2} / 5 \% \mathrm{CO}_{2}$ via a pressurized, 8-chamber, solenoid actuated perfusion system (Automate). Temperature was maintained at $35^{\circ} \mathrm{C}-37^{\circ} \mathrm{C}$ using a TS-4 Peltier effect temperature controller that warmed the inflow tubing and chamber. For digital imaging, the microscope was fitted with a Retiga-1300, cooled, 12-bit, color Bayer mosaic CCD camera (QImaging) with RGB Liquid Crystal Color Filter Module (Spectra). The camera is interfaced with a computer running Compix Image capture and analysis software. All human glands were tested within 15 hours of harvest ( $12 \pm 3$ hours for DC subjects; $10 \pm 5$ hours for HN subjects; $12 \pm 2$ hours for CF subjects).

For overview images of the gland, we used an $\times 4$ objective. For detailed studies of cellular changes in the acini, tubules, and ducts of glands, glands were imaged with an $\times 40$ water immersion lens (numerical aperture, 0.8 ; 2 -mm working distance) and time lapse digital imaging was used to monitor changes with frame rates of 2-30 s-1. At this magnification, the field and focal plane are sufficiently restricted, so that it is usually necessary to pick a single duct, tubule, or acinus for optical imaging.

Serous and mucous cells were distinguished by 2 criteria: location and physical appearance. Cells that were granular when viewed with DIC and that were only seen in the acini of the gland were scored as serous cells; these cells usually appeared to have a smaller apical surface than basolateral surface. Cells in the tubules downstream from the acini appeared smooth when viewed with DIC, and unlike the tapering serous cells, they were typically rectangular when viewed from the side; these were scored as mucous cells. Usually an abrupt transition occurred between the 2 types of cells, sometimes indicated by a constriction. On occasion, we saw acini that appeared to be a continuation of the mucous tubule, with no serous cells that we could discern; these mucous acini have been described previously (36).

The DIC method produces a thin optical slice through an acinus and/ or tubule. We obtained longitudinal optical sections whenever possible to allow observation of linear flow of mucus particles as an independent, qualitative measure of secretion. We expected, on the basis of much other work (e.g., 28, 29), that secreting cells might show volume changes. These were readily observed and could be quantified by making the simple assumptions (based on numerous observations) that tubules are essentially cylinders and acini are their spherical ends (perhaps slightly enlarged); the open portion of the cylinder is the lumen. The longitudinal optical section of the tubules and acini allowed us to measure their outer diameter, lumen diameter, and length (from specified landmarks) before, during, and after stimulation at a number of points along the tubule/acinus. Measurements were made on high-resolution, precalibrated digital images, captured every 2-30 seconds using Compix analysis software. Measurements were only made when 2 criteria were satisfied: both the outer edges of the tubule/ acinus and the corresponding edges of the lumen had to be clearly visible, and (assuming they are cylinders), their initial diameters were maximized by through-focusing, so that we knew we were measuring the center of the acinus/tubule and the lumen.
We used the following rationale for interpreting our data. A transection through a duct, tubule, or acinus would appear as an annulus with an area occupied by cells $=\pi \times\left(\right.$ outer radius ${ }^{2}-$ lumen radius $\left.{ }^{2}\right)$. If our assumption of cylindrical shape was valid, then we measured these radii and so could compute the volume of cells in the annulus for an arbitrary length of tubule (i.e., the thickness of the annulus), which we arbitrarily set to $20 \mu \mathrm{m}$. It was a consistent finding that this volume decreased during stimulation, because the outer radius did not change (or became smaller), while the inner radius (lumen) increased. We refer to this as a net cell volume loss, because we can't know if all of the cells in the annulus respond identically; but if some don't change or increase their volume, then correspondingly larger decreases must occur in other cells to give the aggregate decrease in volume we observed.

These measurements capture only a fraction of the dynamics of gland behavior during stimulation; therefore, video files have been provided as supplemental online material (Supplemental Videos 1-3).

Reagents. Compounds (from Sigma-Aldrich, Teflab, Invitrogen, and SERVA) were made fresh or maintained at $-20^{\circ} \mathrm{C}$. Stock solutions of SubP, phosphoramidon (a metalloproteinase inhibitor that helps prevent breakdown of SubP by endopeptidase), carbachol, VIP, atropine (inhibitor of muscarinic receptors), and clotrimazole were dissolved in sterile distilled water; indomethacin (inhibitor of prostaglandin release) was dissolved in ethanol; and forskolin and BAPTA-AM were dissolved in DMSO. All were diluted 1:1,000 with bath solution (except indomethacin, 1:10,000) immediately before use at the concentrations indicated. The highest DMSO concentration in our experiments was $0.20 \%$, and the highest ethanol concentration was $0.01 \%$. We tested $0.5 \%$ DMSO as vehicle alone with no effect. To stimulate mucosal C fibers, we used a commercially available hot chili pepper oil that contained capsaicin and other irritants (Melina's; Pepper Mill Imports).

Statistics. Data are mean \pm SEM. Unpaired, 2-tailed Student's $t$ test was used to compare the means of different treatment groups unless otherwise indicated. Fisher's exact test was used for $2 \times 2$ contingency tables. A 1-way ANOVA with Tukey-Kramer post-hoc test was used for comparisons of 3 or more data sets. Any difference was considered to be significant when $P$ was less than 0.05 . Curves were fit with Origin software (OriginLab Corporation) using a sigmoid function.

\section{Acknowledgments}

Research was supported by NIH (DK-51817) (to J.J. Wine), the Cystic Fibrosis Foundation, and Cystic Fibrosis Research Inc. J.Y. Choi and M. Khansaheb were recipients of Elizabeth Nash Fellowships. We are very grateful to John Hanrahan and Juan Ianowski, with whom we initiated the study of SubP on gland secretion in mice and whose insights have greatly helped the present work. We thank Tony Nguyen and Kim Tran for valuable technical assistance and for tissue harvesting, Marlene Wine and Kim Tran for help obtaining consents, Lisa Levin and Jackie Zirbes for help with patient information, and Jennifer Lyons for helpful discussions. We especially thank the patients and their families, whose donations of tissues were essential for this research.

Received for publication August 27, 2008, and accepted in revised form February 25, 2009.

Address correspondence to: Jeffrey J. Wine, Cystic Fibrosis Research Laboratory, Room 450, Bldg. 420, Main Quad, Stanford University, Stanford, California 94305-2130, USA. Phone: (650) 725-2462; Fax: (650) 725-5699; E-mail: wine@stanford.edu. 
1. Engelhardt, J.F., et al. 1992. Submucosal glands are the predominant site of CFTR expression in the human bronchus. Nat. Genet. 2:240-248.

2. Engelhardt, J.F., Zepeda, M., Cohn, J.A., Yankaskas, J.R., and Wilson, J.M. 1994. Expression of the cystic fibrosis gene in adult human lung. J. Clin. Invest. 93:737-749.

3. Kreda, S.M., et al. 2005. Characterization of wildtype and deltaF508 cystic fibrosis transmembrane regulator in human respiratory epithelia. Mol. Biol. Cell. 16:2154-2167.

4. Wu, J.V., Krouse, M., and Wine, J.J. 2007. Acinar origin of CFTR-dependent airway submucosal gland fluid secretion. Am. J. Physiol. Lung Cell Mol. Physiol. 292:L304-L311.

5. Wine, J.J., and Joo, N.S. 2004. Submucosal glands and airway defense. Proc. Am. Thorac. Soc. 1:47-53.

6. Jiang, C., Finkbeiner, W.E., Widdicombe, J.H., and Miller, S.S. 1997. Fluid transport across cultures of human tracheal glands is altered in cystic fibrosis. J. Physiol. (Lond.) 501:637-647.

7. Joo, N.S., et al. 2002. Absent secretion to vasoactive intestinal peptide in cystic fibrosis airway glands. J. Biol. Chem. 277:50710-50715.

8. Boucher, R.C. 2007. Airway surface dehydration in cystic fibrosis: pathogenesis and therapy. Annu. Rev. Med. 58:157-170.

9. Knowles, M.R., and Boucher, R.C. 2002. Mucus clearance as a primary innate defense mechanism for mammalian airways. J. Clin. Invest. 109:571-577.

10. Ballard, S.T., and Spadafora, D. 2007. Fluid secretion by submucosal glands of the tracheobronchial airways. Respir. Physiol. Neurobiol. 159:271-277.

11. Ballard, S.T., and Inglis, S.K. 2004. Liquid secretion properties of airway submucosal glands. J. Physiol. 556:1-10.

12. Ballard, S.T., Trout, L., Mehta, A., and Inglis, S.K. 2002. Liquid secretion inhibitors reduce mucociliary transport in glandular airways. Am. J. Physiol. Lung Cell Mol. Physiol. 283:L329-L335.

13. Ballard, S.T., Trout, L., Bebok, Z., Sorscher, E.J., and Crews, A. 1999. CFTR involvement in chloride, bicarbonate, and liquid secretion by airway submucosal glands. Am. J. Physiol. 277:L694-L699.

14. Trout, L., King, M., Feng, W., Inglis, S.K., and Ballard, S.T. 1998. Inhibition of airway liquid secretion and its effect on the physical properties of airway mucus. Am. J. Physiol. 274:L258-L263.

15. Inglis, S.K., Corboz, M.R., and Ballard, S.T. 1998. Effect of anion secretion inhibitors on mucin content of airway submucosal gland ducts. Am. J. Physiol. 274:L762-L766.

16. Inglis, S.K., Corboz, M.R., Taylor, A.E., and Ballard, S.T. 1997. Effect of anion transport inhibition on mucus secretion by airway submucosal glands. Am. J. Physiol. 272:L372-L377.

17. Wine, J.J. 2007. Parasympathetic control of airway submucosal glands: Central reflexes and the airway intrinsic nervous system. Auton. Neurosci. 133:35-54.

18. Ianowski, J.P., Choi, J.Y., Wine, J.J., and Hanrahan, J.W. 2007. Mucus secretion by single tracheal submucosal glands from normal and cystic fibrosis transmembrane conductance regulator CFTR knock-out mice. J. Physiol. 580:301-314.

19. Choi, J.Y., et al. 2007. Synergistic airway gland mucus secretion in response to vasoactive intestinal peptide and carbachol is lost in cystic fibrosis. J. Clin. Invest. 117:3118-3127.

20. Joo, N.S., Irokawa, T., Robbins, R.C., and Wine, J.J. 2006. Hyposecretion, not hyperabsorption, is the basic defect of cystic fibrosis airway glands. J. Biol. Chem. 281:7392-7398.
21. Joo, N.S., et al. 2001. $\mathrm{HCO}_{3}{ }^{-}$transport in relation to mucus secretion from submucosal glands. JOP. 2(4 Suppl.):280-284.

22. Verkman, A.S., Song, Y., and Thiagarajah, J.R. 2003 Role of airway surface liquid and submucosal glands in cystic fibrosis lung disease. Am. J. Physiol. Cell Physiol. 284:C2-C15.

23. Thiagarajah, J.R., Song, Y., Haggie, P.M., and Verkman, A.S. 2004. A small molecule CFTR inhibitor produces cystic fibrosis-like submucosal gland fluid secretions in normal airways. FASEB $J$. 18:875-877.

24. Salinas, D., et al. 2005. Submucosal gland dysfunction as a primary defect in cystic fibrosis. FASEB J 19:431-433.

25. Reid, L. 1960. Measurement of the bronchial mucous gland layer: a diagnostic yardstick in chronic bronchitis. Thorax. 15:132-141.

26. Trout, L., Corboz, M.R., and Ballard, S.T. 2001. Mechanism of substance P-induced liquid secretion across bronchial epithelium. Am. J. Physiol. Lung Cell Mol. Physiol. 281:L639-L645.

27. Dajani, R., et al. 2005. Lysozyme secretion by submucosal glands protects the airway from bacterial infection. Am. J. Respir. Cell Mol. Biol. 32:548-552.

28. Lee, R.J., Limberis, M.P., Hennessy, M.F., Wilson, J.M., and Foskett, J.K. 2007. Optical imaging of Ca2+evoked fluid secretion by murine nasal submucosal gland serous acinar cells. J. Physiol. 582:1099-1124.

29. Lee, R.J., Harlow, J.M., Limberis, M.P., Wilson, J.M., and Foskett, J.K. 2008. HCO3(-) secretion by murine nasal submucosal gland serous acinar cells during Ca2+-stimulated fluid secretion. J. Gen. Physiol. 132:161-183.

30. Phillips, J.E., Hey, J.A., and Corboz, M.R. 2003. Tachykinin NK3 and NK1 receptor activation elicits secretion from porcine airway submucosal glands. Br. J. Pharmacol. 138:254-260.

31. Ianowski, J.P., Choi, J.Y., Wine, J.J., and Hanrahan, J.W. 2008. Substance P stimulates CFTR-dependent fluid secretion by mouse tracheal submucosal glands. Pflugers Arch. 457:529-537.

32. Matsui, H., et al. 1998. Evidence for periciliary liquid layer depletion, not abnormal ion composition, in the pathogenesis of cystic fibrosis airways disease. Cell. 95:1005-1015.

33. Joo, N.S., Wu, J.V., Krouse, M.E., Saenz, Y., and Wine, J.J. 2001. Optical method for quantifying rates of mucus secretion from single submucosal glands. Am. J. Physiol. Lung Cell Mol. Physiol. 281:L458-L468.

34. Joo, N.S., Saenz, Y., Krouse, M.E., and Wine, J.J. 2002. Mucus Secretion from single submucosal glands of pig. Stimulation by carbachol and vasoactive intestinal peptide. J. Biol. Chem. 277:28167-28175.

35. Hislop, A.A., Wharton, J., Allen, K.M., Polak, J.M., and Haworth, S.G. 1990. Immunohistochemical localization of peptide-containing nerves in human airways: age-related changes. Am. J. Respir. Cell Mol. Biol. 3:191-198.

36. Meyrick, B., Sturgess, J.M., and Reid, L. 1969. A reconstruction of the duct system and secretory tubules of the human bronchial submucosal gland. Thorax. 24:729-736.

37. Bijman, J., et al. 1991. Chloride transport in the cystic fibrosis enterocyte. Adv. Exp. Med. Biol. 290:287-294; discussion 294-296.

38. Taylor, C.J., Baxter, P.S., Hardcastle, J., and Hardcastle, P.T. 1988. Failure to induce secretion in jejunal biopsies from children with cystic fibrosis. Gut. 29:957-962.

39. Berschneider, H.M., et al. 1988. Altered intesti- nal chloride transport in cystic fibrosis. FASEB J. 2:2625-2629.

40. Mall, M., et al. 1998. Cholinergic ion secretion in human colon requires coactivation by cAMP. Am. J. Physiol. 275:G1274-G1281.

41. Carew, M.A., and Thorn, P. 2000. Carbachol-stimulated chloride secretion in mouse colon: evidence of a role for autocrine prostaglandin E2 release. Exp. Physiol. 85:67-72.

42. Hosoda, Y., Karaki, S., Shimoda, Y., and Kuwahara, A. 2002. Substance P-evoked $\mathrm{Cl}(-)$ secretion in guinea pig distal colonic epithelia: interaction with PGE(2). Am. J. Physiol. Gastrointest. Liver Physiol. 283:G347-G356.

43. Clarke, L.L., et al. 1994. Relationship of a non-cystic fibrosis transmembrane conductance regulator-mediated chloride conductance to organ-level disease in $\mathrm{Cftr}(-/-)$ mice. Proc. Natl. Acad. Sci. U. S. A. 91:479-483.

44. Rogers, D.F., Alton, E.W., Dewar, A., Lethem, M.I., and Barnes, P.J. 1993. Impaired stimulus-evoked mucus secretion in cystic fibrosis bronchi. Exp. Lung Res. 19:37-53.

45. Clarke, L.L., et al. 2004. Abnormal Paneth cell granule dissolution and compromised resistance to bacterial colonization in the intestine of CF mice. Am. J. Physiol. Gastrointest. Liver Physiol. 286:G1050-G1058.

46. Quinton, P.M. 2008. Cystic fibrosis: impaired bicarbonate secretion and mucoviscidosis. Lancet. 372:415-417.

47. Song, Y., Salinas, D., Nielson, D.W., and Verkman, A.S. 2006. Hyperacidity of secreted fluid from submucosal glands in early cystic fibrosis. Am. J. Physiol. Cell Physiol. 290:C741-C749.

48. Soltoff, S.P., McMillian, M.K., Cantley, L.C., Cragoe, E.J., Jr., and Talamo, B.R. 1989. Effects of muscarinic, alpha-adrenergic, and substance $P$ agonists and ionomycin on ion transport mechanisms in the rat parotid acinar cell. The dependence of ion transport on intracellular calcium. J. Gen. Physiol. 93:285-319.

49. Lamb, J.P., and Sparrow, M.P. 2002. Three-dimensional mapping of sensory innervation with substance $\mathrm{p}$ in porcine bronchial mucosa: comparison with human airways. Am. J. Respir. Crit. Care Med. 166:1269-1281.

50. Rogers, C.S., et al. 2008. The porcine lung as a potential model for cystic fibrosis. Am. J. Physiol. Lung Cell Mol. Physiol. 295:L240-L263.

51. Rogers, C.S., et al. 2008. Production of CFTRnull and CFTR-DeltaF508 heterozygous pigs by adeno-associated virus-mediated gene targeting and somatic cell nuclear transfer. J. Clin. Invest. 118:1571-1577.

52. Tachado, S.D., Akhtar, R.A., Yousufzai, S.Y., and Abdel-Latif, A.A. 1991. Species differences in the effects of substance P on inositol trisphosphate accumulation and cyclic AMP formation, and on contraction in isolated iris sphincter of the mammalian eye: differences in receptor density. Exp. Eye Res. 53:729-739.

53. Quinton, P.M. 2007. Too much salt, too little soda: cystic fibrosis. Sheng Li Xue Bao. 59:397-415.

54. Mitchell, R.A., Herbert, D.A., Baker, D.G., and Basbaum, C.B. 1987. In vivo activity of tracheal parasympathetic ganglion cells innervating tracheal smooth muscle. Brain Res. 437:157-160.

55. Scanlon, M., Williams, D.A., and Fay, F.S. 1987. A Ca2+-insensitive form of fura-2 associated with polymorphonuclear leukocytes. Assessment and accurate $\mathrm{Ca} 2+$ measurement. J. Biol. Chem. 262:6308-6312. 